OPEN ACCESS

Edited by:

Nurit Hollander,

Tel Aviv University, Israel

Reviewed by:

Tengfei Liu,

Heidelberg University, Germany

Panagiotis F. Christopoulos,

Oslo University Hospital, Norway

*Correspondence:

Hui Xie

huixie@csu.edu.cn

Specialty section:

This article was submitted to

Cancer Immunity

and Immunotherapy,

a section of the journal

Frontiers in Oncology

Received: 23 July 2020 Accepted: 05 November 2020 Published: 10 December 2020

Citation:

Luo Z-W, Liu P-P, Wang Z-X, Chen $C-Y$ and Xie $H$ (2020)

Macrophages in Osteosarcoma

Immune Microenvironment: Implications for Immunotherapy.

Front. Oncol. 10:586580. doi: 10.3389/fonc.2020.586580

\section{Macrophages in Osteosarcoma Immune Microenvironment: Implications for Immunotherapy}

\author{
Zhong-Wei Luo ${ }^{1,2}$, Pan-Pan Liu ${ }^{3}$, Zhen-Xing Wang ${ }^{1,2}$, Chun-Yuan Chen ${ }^{1,2}$ \\ and Hui Xie ${ }^{1,2,4,5,6,7 *}$
}

${ }^{1}$ Department of Orthopedics, Xiangya Hospital, Central South University, Changsha, China, ${ }^{2}$ Movement System Injury and Repair Research Center, Xiangya Hospital, Central South University, Changsha, China, ${ }^{3}$ The Department of Dermatology, Xiangya Hospital, Central South University, Changsha, China, ${ }^{4}$ Department of Sports Medicine, Xiangya Hospital, Central South University, Changsha, China, ${ }^{5}$ Hunan Key Laboratory of Organ Injury, Aging and Regenerative Medicine, Changsha, China, ${ }^{6}$ Hunan Key Laboratory of Bone Joint Degeneration and Injury, Changsha, China, ${ }^{7}$ National Clinical Research Center for Geriatric Disorders, Xiangya Hospital, Central South University, Changsha, China

Osteosarcoma is a malignant primary bone tumor commonly occurring in children and adolescents. The treatment of local osteosarcoma is mainly based on surgical resection and chemotherapy, whereas the improvement of overall survival remains stagnant, especially in recurrent or metastatic cases. Tumor microenvironment (TME) is closely related to the occurrence and development of tumors, and macrophages are among the most abundant immune cells in the TME. Due to their vital roles in tumor progression, macrophages have gained increasing attention as the new target of tumor immunotherapy. In this review, we present a brief overview of macrophages in the TME and highlight the clinical significance of macrophages and their roles in the initiation and progression of osteosarcoma. Finally, we summarize the therapeutic approaches targeting macrophage, which represent a promising strategy in osteosarcoma therapies.

Keywords: osteosarcoma, tumor microenvironment, macrophages, tumor-associated macrophages(TAMs), immunotherapy

\section{INTRODUCTION}

Osteosarcoma is one of the most common aggressive malignancies of bone tumors in children and adolescents $(1,2)$. With improved surgical techniques and neoadjuvant chemotherapy, limb-salvage surgery combined with systemic chemotherapy has been a better option than simply amputation. These multidisciplinary combination treatments have increased 5-year survival to $60-70 \%$ in nonmetastatic patients with osteosarcoma (3). Despite great success in osteosarcoma management, improvements in survival rates in the last decade were limited (4). Moreover, tumor metastasis or recurrence of patients have consistently shown poorer outcomes and remain unresolved (5). As such, new therapeutic strategies are urgently needed.

Recently attention has been paid to the tumor microenvironment (TME), which plays a crucial role in cancer initiation and progression $(6,7)$. TME is constituted by tumor cells, fibroblasts, endothelial cells, immune cells, various signaling molecules, and extracellular matrix (8). Due to the complexity and heterogeneity of cells, TME has diverse effects during different stages of cancer progression and 
metastasis $(9,10)$. Tumor-associated macrophages (TAMs), as the primary immune cells in the TME, have been identified as a prognostic marker and a new target in tumor immunotherapy (11). A thorough and comprehensive understanding of macrophages may provide new insights and potential therapeutic approaches for osteosarcoma (12-14). Therefore, we briefly introduce the origin, polarization, and regulation of macrophages. Then we focus on the relationship between the polarization status and prognosis of macrophages in osteosarcoma and elaborate on the mechanisms of macrophages in the development and metastasis of osteosarcoma. Finally, targeting macrophages therapy in osteosarcoma is also discussed.

\section{OVERVIEW OF MACROPHAGES}

Macrophages are generally thought to be developed from the hematopoietic stem cells (HSCs) and derived from the myeloidmonocytic lineage. They are initially recruited from the peripheral blood to eliminate harmful pathogens, infection and inflammation $(15,16)$. Nevertheless, in recent years, the increasing evidence indicates that tissue-resident macrophages develop from embryos before the appearance of HSCs and maintain self-renewal proliferation $(17,18)$. Thus the origin of macrophages can be simply divided into two categories: one is tissue-resident macrophages mainly derived from the yolk sac and fetal liver; another is originated from bone marrow-derived blood monocytes (19).

Although the content may significantly vary in different tumors, tumor-associated macrophages (TAMs) are primary immune cells present in the tumor microenvironment. Both circulating monocytes and tissue-resident macrophages contribute to the accumulation of TAMs. The secreted chemokines from tumor cells and stromal cells, such as macrophage colony-stimulating factor (M-CSF) and C-C motif ligand 2 (CCL-2), can induce and recruit monocytes to the tumor microenvironment $(20,21)$. Notably, it has been found that TAMs were recruited by interleukin-34 (IL-34) released from osteosarcoma cells and infiltrated massively into osteosarcoma tissues (22). These monocytes can differentiate into macrophages under the stimulation of local signal molecules (19).

Macrophages are plastic to multiple signals under the specific TME. The activated macrophages, distinct from tissue-resident macrophages, develop specific phenotypes that show different polarization states and functions (20,23). Traditionally, a dichotomous spectrum including M1 and M2 phenotypes represented two polarized terminals of the broad range of macrophage activation: classically activated macrophages (M1), stimulated by interferon- $\gamma$, lipopolysaccharide (LPS) and Tolllike receptor (TLR); and alternatively activated macrophages (M2), activated by cytokines such as IL-4 and IL-13 and other signal molecules $(17,18)$. Nevertheless, it is also worth noting that macrophages are a heterogeneous population of myeloid cells and have been recognized as a complex spectrum of activation states, represented by a mixed or intermediate phenotype expressing both M1 and M2 markers albeit to a different extent $(20,21)$. This spectrum model of macrophages suggests a continuum of functional status and can better generalize the real state of macrophage activation in the microenvironment (24-26). Furthermore, due to the lack of specificity of marker expression, the classification based on polarization status via a single M1/M2 marker may simplify the complexity of macrophages. For instance, Arginase- 1 can be upregulated upon M1 (LPS) or M2 (IL-4) stimulation (17).

Similarly, due to the plasticity and heterogeneity, TAMs are characterized by pro- or anti-tumor activity according to the tumor types and their interactions in the TME $(21,27)$. TAMs showing M1-like features have the potential to kill tumor cells and enhance the immune response. However, TAMs, generally exhibiting an M2-like immunosuppressive phenotype in most tumors, tend to promote angiogenesis and facilitate extravascular invasion and immune escape, eventually leading to tumor progression and metastasis $(28,29)$. First, TAMs can promote tumor angiogenesis (29). Emerging studies have found that the amount of TAMs in the tissues of various tumors (such as breast cancer, lung cancer, glioma, gastric cancer, et al.) is positively correlated with the number and density of tumor blood vessels $(20,30)$. Various pro-angiogenic factors, such as vascular endothelial growth factor (VEGF), fibroblast growth factor (FGF) and matrix metallopeptidase 9 (MMP-9), are secreted to participate in the process of tumor angiogenesis (31). Second, TAMs can also mediate immunosuppression via interaction with various immune effector cells. It is currently reported that TAMs express the ligand receptors of programmed death 1 (PD-1) and cytotoxic T lymphocyte-associated antigen-4 (CTLA-4), which inhibit the activation of T cells. Studies have found that TAMs can produce not only immunosuppressive cytokines (IL-10 and transforming growth factor- $\beta$ (TGF- $\beta$ )), but also chemokines such as CCL5, CCL20, and CCL22 that recruit regulatory T cells into tumor tissues $(20,29)$. Third, TAMs support invasion and metastasis of tumor cells by increasing vascular extravasation, promoting survival and growth of metastatic cells, and suppressing effector $\mathrm{T}$ cells $(20,32)$. Ultimately pre-metastatic niche was established at distant sites in specific metastatic organs with the aid of macrophages. In the later sections, existing studies on the roles of macrophages in osteosarcoma will be further discussed.

\section{MACROPHAGES AND OSTEOSARCOMA}

\section{Macrophage Phenotypes in Osteosarcoma}

Macrophages are one of the crucial immune components in the osteosarcoma niche. As described above, macrophages demonstrate a broad spectrum of activation status. Researchers mostly resort to the markers of the polarized extremes or a variety of cellular deconvolution methodologies to depict the heterogeneity of macrophages in osteosarcoma. A comprehensive study described that $\mathrm{CD} 14^{+} / \mathrm{CD} 68^{+}$TAMs represent the main 
infiltrating immune cell types in bone sarcomas, including osteosarcoma (33). Similarly, an infiltration landscape of immune cells using the CIBERSORT algorithm showed a high ratio of M0 and M2 macrophages in osteosarcoma tissues in the TARGET cohort (34). Gene expression analysis and CD209 staining also confirmed the enrichment of M2 macrophages in human osteosarcoma tissues (35).

The progression and metastasis of osteosarcoma may induce an imbalance of macrophage subtype populations (36). It was reported that M2-like macrophage marker molecules, including CD206, Arg-1, and Ym-1, were significantly upregulated in the osteosarcoma tissues compared with non-tumor tissues (37). Another independent study also showed higher frequencies of $\mathrm{CD}_{163}{ }^{+}$macrophages in tumor-infiltrating cells from resected tumors than in peripheral blood immune cells (38).

Notably, the infiltration of macrophage is also different in metastatic osteosarcoma. For instance, Han's group observed that CD68 was significantly higher in osteosarcoma tissues of patients with detectable metastasis than patients without metastasis (39). Furthermore, the level of CD68 was also upregulated in human lung metastases than corresponding primary osteosarcoma lesions, while CD163, a biomarker of M2 macrophage, showed no significant difference (39). Additionally, Dumars et al. revealed a higher infiltration of the INOS $^{+}$M1 subtype in osteosarcoma tumors of non-metastatic patients (40).

Accordingly, some previous preclinical studies have come to the same conclusions. In a mouse model of human osteosarcoma implantation, macrophages were recruited into the tumor tissue and polarized into the M2 subset (41). Furthermore, it was found that a large number of $\mathrm{F} 4 / 80^{+}$cells were infiltrated into the metastatic pulmonary tissue (39) and M2-type (CD206 $\left.{ }^{+} \mathrm{MHC}-\mathrm{II}^{-}\right)$ macrophages were increased in the metastatic mouse lung tissue, but M1 (CD206 ${ }^{-} \mathrm{MHC}-\mathrm{II}^{+}$) remains unchanged (42). The levels of infiltrated M1 or M2 may vary in the primary and metastatic lesions (literature summarized in Table 1), suggesting their different role in the development of osteosarcoma.

\section{Relationship Between Macrophage Phenotypes and Clinical Prognosis}

Macrophages have diverse functions and show plasticity in response to microenvironments. Mounting evidence suggests that macrophages facilitate tumor progression and metastasis $(29,48)$. In contrast to the tumor-supporting role for TAMs in many other tumor types, higher numbers of infiltrating TAMs correlated with better survival in osteosarcoma.

Several studies confirmed that the infiltration of macrophages, regardless of their polarization phenotype, exhibited positive clinical outcomes in osteosarcoma patients. Buddin et al. proved that TAMs defined as CD14-expressed cells were associated with metastasis suppression and better overall survival in high-grade osteosarcoma patients (43). A study based on the RNA-seq data and CIBERSORT algorithm analysis showed that higher M1 and M2 macrophages were associated with improved overall survival in prognosis (34). Consistent with this study, another bioinformatics analysis using different clinical dataset also observed that $\mathrm{M} 0$ macrophages were correlated with good prognosis (44). Similarly, Gomez-Brouchet et al. reported that upregulated CD163 TAM was significantly related to better overall survival and more prolonged metastasis progression-free survival (MPFS), and a similar trend was also observed for patients with higher levels of CD68-positive cell though not significant (45).

However, the relationship between CD68 positive macrophages (used to represent pan-macrophages) and the prognosis was controversial. Dumars et al. found that $\mathrm{CD}^{+} 8^{+} \mathrm{TAM}$ infiltration was positively correlated with better overall survival (40). In contrast, increased $\mathrm{CD}^{+} 8^{+}$macrophages in patients were reported to have poorer five-year-event free survival by Koirala et al. (46). Meanwhile, some studies also determined that the presence of M2-like macrophage showed opposite effects. Su et al. observed that CCL18/CD68 double-positive macrophages were significantly correlated with lung metastasis and worse prognosis in osteosarcoma patients (47). Intriguingly, Yang et al. also reported that M2 macrophages were correlated with poor prognosis in osteosarcoma patients, as seen in other types of tumors (44).

These discrepancies may be due to multiple factors, such as the different treatments before surgery or diverse experimental methods and details. For instance, Han et al. (39) adopted the surgically resected specimens after chemotherapy, while Gomez et al. (45) performed tissue analysis on the diagnostic biopsies from osteosarcoma patients without chemotherapy. Some studies included patients from public databases like the TARGET cohort (34) or GEO dataset (44), who varied largely in age, gender, tumor stage, tumor location, histologic grading, and metastatic status, resulting in unconformity in observing evidence (34). Meanwhile, the lack of consistency in macrophage markers used, as well as the lack of specificity of the selection of the current markers, may have contributed to the inconsistent results. Different markers were applied to serve as a panmacrophage marker such as CD68 and CD14 in different studies, as described above. However, CD68 may be expressed on other non-myeloid origin cells, such as granulocytes, dendritic cells $(49,50)$. Apart from monocytes and macrophages, neutrophils and dendritic cells are positive for the marker CD14 (46). Most studies used CD163 as an M2-type TAM marker, yet CD163 expression may also be found in dendritic cells $(51,52)$. Notably, the activation status may also confuse the results. For example, Arginase-1 can be upregulated upon M1 (LPS) stimulation (17).

These studies suggested that the relationship between macrophage phenotypes and clinical prognosis in osteosarcoma was more complex than previously thought (literature summarized in Table 1). Based on the available evidence, we can conclude that macrophages are associated with the prognosis of osteosarcoma, whereas the adequate and homogeneous phenotypic characterization of macrophage subpopulations is lacking. These studies indicate macrophages exert distinct effects in osteosarcoma, though the specific subsets are still unclear and need comprehensive and thorough investigations. Moreover, osteosarcoma disease progression causes dynamic regulation of macrophage activation 
TABLE 1 | Macrophage phenotypes and their relation to clinical prognosis in osteosarcoma.

\begin{tabular}{|c|c|c|c|c|c|}
\hline Species & $\begin{array}{l}\text { Detection } \\
\text { Methods }\end{array}$ & $\begin{array}{l}\text { Markers of } \\
\text { Phenotypes }\end{array}$ & Different Phenotypes of Infiltrating Macrophages & Prognosis Impact & Ref. \\
\hline Human & $\begin{array}{l}\text { Microarray } \\
\text { and IHC } \\
\text { analysis }\end{array}$ & $\begin{array}{l}\text { Pan-marker: CD14; } \\
\text { M1: HLA-DR } \alpha, M 2: \\
\text { CD163 }\end{array}$ & Higher CD14 expression in the non-metastasis group & $\begin{array}{l}\text { Higher } \mathrm{CD}_{14}^{+} \text {macrophages correlated with } \\
\text { metastasis suppression and better OS while } \\
\text { M1or M2 not significant }\end{array}$ & $(43)$ \\
\hline Human & $\begin{array}{l}\text { CIBERSORT } \\
\text { algorithm }\end{array}$ & Not mentioned & $\begin{array}{l}\mathrm{M} 0(0.23 \pm 0.1) \text { and } \mathrm{M} 2(0.24 \pm 0.13) \text { fraction of infiltrating } \\
\text { immune cells }\end{array}$ & Higher M1 and M2 macrophages with better OS & (34) \\
\hline Human & $\begin{array}{l}\text { CIBERSORT } \\
\text { algorithm }\end{array}$ & Not mentioned & Not mentioned & $\begin{array}{l}\text { Higher M0 and lower M2 macrophages with } \\
\text { better prognosis }\end{array}$ & $(44)$ \\
\hline Human & $\mathrm{IHC}$ analysis & $\begin{array}{l}\text { M2:CD163; Pan- } \\
\text { marker: CD68 }\end{array}$ & $\begin{array}{l}\text { High CD163 staining rate ( } 43.8 \%) \text { and high CD68 staining } \\
\text { rate }(23.4 \%)\end{array}$ & $\begin{array}{l}\text { Higher CD163 macrophages with better OS and } \\
\text { MPFS }\end{array}$ & $(45)$ \\
\hline Human & $\mathrm{IHC}$ analysis & $\begin{array}{l}\text { Pan-marker: CD68; } \\
\text { M1: iNOS }\end{array}$ & $\begin{array}{l}\text { Higher } \mathrm{INOS}^{+} \text {macrophages in primary tumor tissues of } \\
\text { patients of non-metastasis group }\end{array}$ & Higher CD68+ macrophages with Better OS & (40) \\
\hline Human & $\mathrm{IHC}$ analysis & Pan-marker: CD68 & Not mentioned & $\begin{array}{l}\text { Higher }{\text { CD } 68^{+}}^{+} \text {macrophage with poorer five year- } \\
\text { EFS }\end{array}$ & (46) \\
\hline Human & $\mathrm{HC}$ analysis & $\begin{array}{l}\text { Pan-marker: CD68; } \\
\text { M2:CCL18 }\end{array}$ & $\begin{array}{l}\text { Higher CD68 in lung metastasis than primary } \\
\text { osteosarcoma tissues }\end{array}$ & $\begin{array}{l}\text { Higher } \mathrm{CCL} 18^{+} \mathrm{CD} 68^{+} \text {macrophages with poorer } \\
\text { prognosis }\end{array}$ & $(47)$ \\
\hline Human & $\mathrm{IHC}$ analysis & $\begin{array}{l}\text { Pan-marker: CD14, } \\
\text { CD68 }\end{array}$ & $\begin{array}{l}\text { ratio of } \mathrm{CD} 14^{+} / \mathrm{CD} 68^{+} \text {TAMs relative to } \mathrm{CD} 45^{+} \text {cell }(6- \\
25 \%)\end{array}$ & Not mentioned & (33) \\
\hline Human & $\begin{array}{l}\text { IHC analysis } \\
\text { Expression } \\
\text { analysis of } \\
\text { GEO data }\end{array}$ & $\begin{array}{l}\text { M2: CD209 } \\
\text { M2: CD163, MRC1 } \\
\text { and CCR2 }\end{array}$ & $\begin{array}{l}\text { CD209 positive staining rate }(78.57 \%) \\
\text { higher gene expression levels of CD163, MRC1 and CCR2 } \\
\text { in tumor }\end{array}$ & $\begin{array}{l}\text { Not mentioned } \\
\text { Not mentioned }\end{array}$ & (35) \\
\hline Human & $\begin{array}{l}\mathrm{IHC}, \mathrm{PCR} \text { and } \\
\text { WB analysis }\end{array}$ & $\begin{array}{l}\text { M2: CD206, Arg-1 } \\
\text { and Ym-1 }\end{array}$ & $\begin{array}{l}\text { Upregulation of CD206, Arg-1 and Ym-1 in osteosarcoma } \\
\text { tissue than adjacent non-tumor tissue }\end{array}$ & Not mentioned & (37) \\
\hline Human & FACS analysis & $\begin{array}{l}\text { Pan-marker: CD14; } \\
\text { M2:CD163 }\end{array}$ & $\begin{array}{l}\text { Higher } \mathrm{CD} 14^{+} / \mathrm{CD} 163^{+} \text {macrophages in tumors than } \\
\text { peripheral blood }\end{array}$ & Not mentioned & (38) \\
\hline Human & IHC analysis & $\begin{array}{l}\text { Pan-marker: CD68; } \\
\text { M1: iNOS; M2: } \\
\text { CD163 }\end{array}$ & $\begin{array}{l}\text { Higher CD68 }{ }^{+} \text {macrophages in primary tumor tissues of } \\
\text { patients with metastasis } \\
\text { Higher CD68, lower iNOS and unchanged CD163 in } \\
\text { metastasis than corresponding primary osteosarcoma } \\
\text { tissues }\end{array}$ & $\begin{array}{l}\text { Not mentioned } \\
\text { Not mentioned }\end{array}$ & (39) \\
\hline $\begin{array}{l}\text { NOD/ } \\
\text { SCID } \\
\text { mice }\end{array}$ & FACS analysis & $\begin{array}{l}\text { Pan-marker: F4/80; } \\
\text { M2: CD163 }\end{array}$ & $\begin{array}{l}\text { Upregulation of } \mathrm{CD} 163^{+} / \mathrm{F} 4 / 80^{+} \text {in } 3 \text { weeks after tumor } \\
\text { implantation }\end{array}$ & Not mentioned & $(41)$ \\
\hline $\begin{array}{l}\text { BALB/c } \\
\text { nude } \\
\text { mice }\end{array}$ & $\mathrm{HC}$ analysis & Pan-marker: F4/80 & $\begin{array}{l}\text { Higher } \mathrm{F} 4 / 80^{+} \text {cells in lung metastases than corresponding } \\
\text { primary osteosarcoma tissues }\end{array}$ & Not mentioned & (39) \\
\hline $\begin{array}{l}\mathrm{BALB} / \mathrm{c} \\
\text { mice }\end{array}$ & FACS analysis & $\begin{array}{l}\text { M1: MHC-II; M2: } \\
\text { CD206 }\end{array}$ & 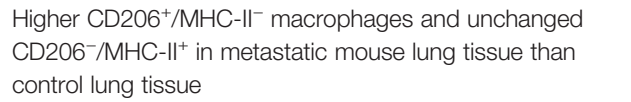 & Not mentioned & $(42)$ \\
\hline
\end{tabular}

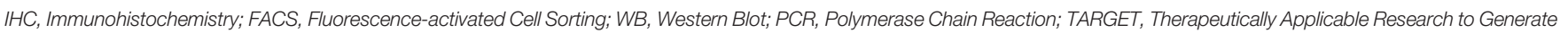
Effective Treatments; GEO, Gene Expression Omnibus.

and reversion; thus, individual markers may not accurately evaluate the multifaceted and complex nature of the macrophage population (32). Harnessing new strategies, such as cell-fate mapping, single-cell sequencing, multicolor immunofluorescence, and macrophage lineages targeting, may uncover the full spectrum of macrophage activation and give a landscape of the osteosarcoma tissue. Technical standardization and validation in a large scale of a clinical cohort with similar treatment and comparable clinical stages are required before the use of M1/M2 markers (53).

\section{The Role of Macrophages in Osteosarcoma Inflammation Modulation}

The inflammatory microenvironment is now recognized as an essential factor contributing to carcinogenesis, tumor metastasis, and treatment resistance $(54,55)$. However, inflammation in the microenvironment of osteosarcoma was recognized to have anti- tumor effects. It has been reported that post-operative infection was associated with improved survival in osteosarcoma patients $(56,57)$. Coley's Toxins, which contained heat-killed bacteria or bacterial products, were utilized to treat bone sarcomas in the late 19 th century $(58,59)$. Similarly, muramyl tripeptide, a synthetic derivative of the bacteria cell wall, was shown to play a positive role in treating osteosarcoma by activation of macrophage $(58,60)$. Therefore, macrophages, as the primary inflammatory cells stimulated by infection, may contribute to anti-tumor immunity (61).

Inflammation may enhance anti-tumor effects by increasing the level of infiltrating macrophages and secreting cytokine. A study based on chronic bacterial osteomyelitis mice model demonstrated that infection increased the number of TAMs and inhibited the growth of tumors in mice via regulating innate immune response elicited by macrophages. Moreover, the depletion of macrophages reversed these anti-tumor 
responses (62). Besides, infection upregulates the cytokine secretion of inflammatory macrophages, including tumor necrosis factor- $\alpha$ (TNF- $\alpha$ ) and interferon- $\gamma$ (IFN- $\gamma$ ), and reactivate the immune system towards anti-tumor response to attenuate immunosuppression induced by osteosarcoma (63). Although these models cannot precisely mimic the local inflammatory microenvironment of osteosarcoma, these preclinical researches, together with the above clinical data, provide a new understanding of the role of macrophages and the inflammatory response in osteosarcoma.

\section{Involvement in Chemotherapy Resistance}

Over the past 30 years, the application of adjuvant and neoadjuvant chemotherapy has significantly improved the 5year survival rate to $60-70 \%$ for patients with osteosarcoma (3, 64). Despite treatment with chemotherapy, the 5 -year event-free survival (EFS) in patients with recurrent osteosarcoma was 15$20 \%$, and it seems unchanged over the years $(3,65)$.

Although the mechanisms are uncertain, scholars have found that macrophages are closely linked to tumor resistance to chemotherapy (50). Chemotherapeutic drugs can inhibit tumorigenesis by blocking proliferation or promoting apoptosis of tumor cells while they induce tissue damage that inevitably activates macrophages' tissue repair activities, resulting in pro-tumoral effects and drug resistance $(66,67)$. TAMs have been shown to hamper chemotherapy-induced antitumor responses in different ways, as illustrated in Figure 1. First, TAMs can sustain cell survival by secreting cytokines, growth factors, and exosomes (68-70). Those factors may contribute to the activation of anti-apoptotic programs and regulation of CSC activities (71). It was also found that macrophages protected against Taxol-induced tumor cell death partially by expressing cathepsins B and S (72). Second, immunosuppression induced by macrophages is also associated with chemotherapy tolerance of the tumors. DeNardo et al. found that inhibition of macrophage by CSF1R antagonists improved the survival of mammary tumor-bearing mice to paclitaxel by $\mathrm{CD}^{+}$T-cell-dependent mechanisms (73). Further, Ruffell et al. confirmed that IL-10 secreted by M2-type macrophages inhibits the expression of IL-12 by dendritic cells, thereby blocking the response of $\mathrm{CD}^{+} \mathrm{T}$ cells (74). Third, macrophages may also affect the vascularization and indirectly regulate the tumor sensitivity to chemotherapy $(75,76)$. VEGF-A clearance in macrophages led to normalized vascular growth and enhanced the sensitivity of Lewis Lung Carcinoma tumors to cytotoxic drugs like cyclophosphamide and cisplatin (77).

Furthermore, the roles of macrophages in chemo-resistance were evidenced by macrophage-targeting therapies (78). For instance, $\mathrm{Lu}$ et al. reported that the depletion of TAMs by CSF-1R inhibitors significantly improved the effects of docetaxel in a murine epithelial ovarian cancer model (79). Along the same lines, live imaging has demonstrated that the treatment with doxorubicin or cisplatin is improved in mice lacking CCR2 ${ }^{+}$TAMs (80). In the light of different cytotoxic agents and types of tumor, mechanisms accounting for TAM induced chemo-resistance need further investigation.

Several studies have confirmed this association between macrophages and chemo-resistance of osteosarcoma cells. Infiltrating $\mathrm{CD}^{+} 8^{+}$cells were higher in tumor tissues of osteosarcoma patients who were poorly reactive to neoadjuvant chemotherapy. Moreover, after treatment with chemotherapy medications, macrophages secreted IL-1 $\beta$, which could activate downstream cancer signaling pathways and reduce the sensitivity of osteosarcoma to chemotherapeutic drugs. Moreover, blockage of the receptor of IL-1 $\beta$ restored the drug effects (81). Similarly, exosomes released by macrophages promoted proliferation, invasion and drug-resistance of osteosarcoma cells via the activation of AKT signaling, which has been widely recognized as a critical pathway mediated tumor progression (82). Those studies revealed that the secretome of macrophages might play a

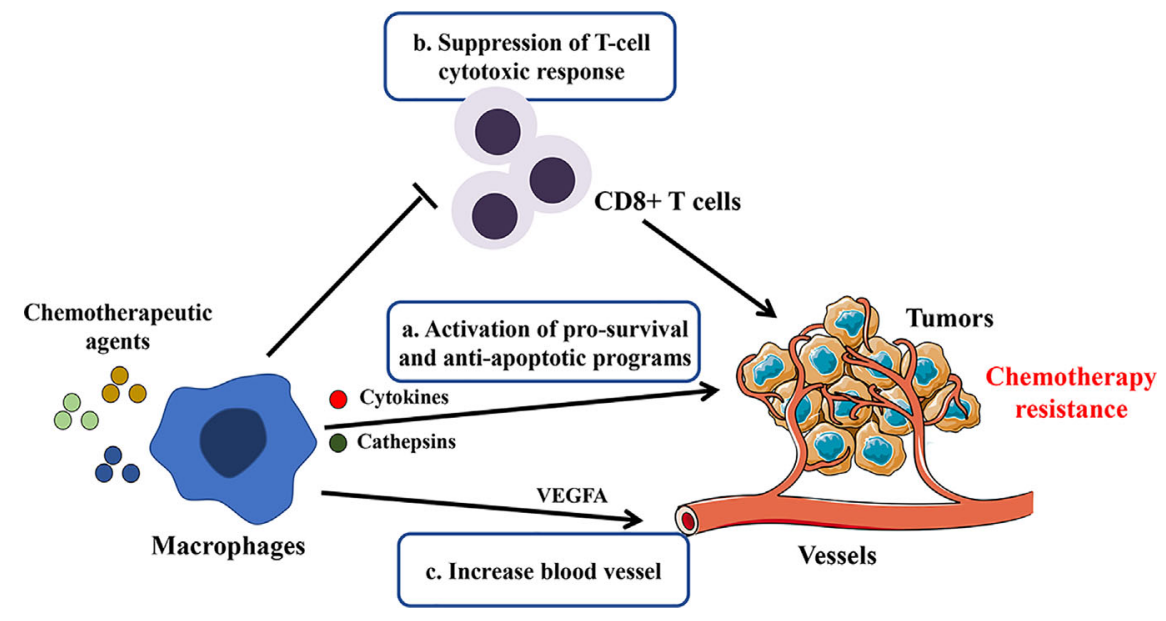

FIGURE 1 | Potential mechanisms involved in macrophage-mediated resistance to chemotherapy. By secreting cytokines, growth factors, cathepsins, and exosomes or direct contact with tumor cells, TAMs blunt chemotherapeutic drugs' efficacy by the following mechanisms: a. sustaining tumor cell survival; b. promoting immunosuppression; c. inducing tumor re-vascularization. 
significant role in drug-resistance in osteosarcoma progression as in other tumors. Targeting macrophage provides potential strategies for improving the efficacy of neoadjuvant chemotherapy for osteosarcoma.

\section{Involvement in Metastasis}

It has been discovered that the number and varied polarization status of infiltrating macrophages were strongly correlated to the prognosis of osteosarcoma patients, as described above (39, 40, 43). Though previous studies came to inconsistent conclusions, macrophages were shown to enhance the metastatic process in osteosarcoma. Maloney et al. demonstrated that macrophage promoted the invasion of osteosarcoma cells and contributed to pulmonary metastasis in the animal model (42). Macrophages within the metastatic lung niche were altered to pro-tumor M2 $\left(\mathrm{MHC} \mathrm{II}^{-} / \mathrm{CD} 206^{+}\right.$) phenotype and enhanced metastatic progression after the removal of the primary osteosarcoma tumor (83).

TAMs facilitate metastatic processes of osteosarcoma via several mechanisms. Su et al. found that CCL18 predominantly secreted by M2-type TAMs promotes proliferation and metastasis of osteosarcoma. Moreover, these effects were attributed to the upregulation of the $\operatorname{lncRNA} \mathrm{UCA} 1 / \mathrm{Wnt} / \beta$ catenin pathway that mediated the tumor-promoting role in different types of tumors (47). Zhou et al. reported that M2 macrophages promoted the metastasis of osteosarcoma through secretion of matrix metalloproteinase 12 (MMP-12), which have been recognized as a metastasis-related factor and participate in degrading extracellular matrix (84). TAMs facilitated the expression of cyclooxygenase 2 (COX-2) of osteosarcoma cells and activate the COX-2/STAT3 axis and epithelial-mesenchymal transition (EMT) to promote osteosarcoma invasion and lung metastasis. Furthermore, blocking STAT3 or COX-2 could prevent the promoting-tumor effects of TAMs (39).

From clinical observations and preclinical studies, we can infer that TAMs, particularly M2-type macrophages, play a vital role in osteosarcoma invasion and metastasis.

\section{Crosstalk Within the Microenvironment}

In tumor microenvironments, the interaction between macrophages and other cells in osteosarcoma TME participates in the disease progress of osteosarcoma. As a part of their survival strategies, tumor cells often resort to cunning mechanisms to manipulate the macrophages and create an immunosuppressive, tumor-promoting microenvironment (85). Some studies demonstrated that osteosarcoma cells enhanced the recruitment of macrophages by secretion of cytokine. The increasing chemokine ligand 5 (CCL5) production by human osteosarcoma cells was reported to promote macrophages recruitment (86). Monocyte chemoattractant protein-1 (MCP-1, also called CCL2) expressed by osteosarcoma participated in the regulation of macrophage recruitment and infiltration via the MCP-1/CCR2 axis (87). IL-34 was released by osteosarcoma cells and promoted the recruitment of M2-TAMs into the tumor tissue, thus promote tumor growth and metastasis (22).

Interestingly, metastatic osteosarcoma cells display a more malignant phenotype via exosomal communication with macrophages. These exosomes significantly increased M2 macrophage-related cytokines such as IL10 and transforming growth factor-beta 2 (TGFB2), and modulate macrophages to a tumor-promoting M2 phenotype. This conversion contributed to the inhibition of macrophage-mediated tumoricidal functions like decreased phagocytosis, efferocytosis and direct tumor cell killing effects (88).

Macrophages may also influence the function of $\mathrm{T}$ cells. Han et al. revealed that the presence of M2-type $\left(\mathrm{CD}_{163}{ }^{+}\right)$macrophages was correlated with the frequency of $\mathrm{TIM}-3^{+} \mathrm{PD}-1^{+} \mathrm{T}$ cells representing the exhausted and immunosuppressive $\mathrm{T}$ cell subset. And these macrophages contributed to the impairment of $\mathrm{T}$ cell proliferation and production of pro-inflammatory cytokine and hence aggravated immunosuppression. Additionally, selective depletion of CD163(+) macrophages revive T cell function (38).

The initiation and progression of osteosarcoma result from a complex interaction of the integral microenvironment constructed by several types of cells and matrix (89). Further intensive studies would provide a better understanding of the interplay between macrophages and other cells.

\section{Macrophage Targeting Therapeutics in Osteosarcoma}

\section{Macrophage Depletion and Recruitment Targeting}

One of the macrophage-targeting treatments is to reduce the number of infiltrating TAMs. The main therapeutic strategies include direct depletion of macrophages and reduction of monocyte/macrophage recruitment. After being engulfed, clodronate liposomes can eliminate macrophages via the induction of apoptosis (90). Regarding the preclinical studies of osteosarcoma, researchers have confirmed that the clodronate liposomes treated mice demonstrated reduced lung metastasis of osteosarcoma $(42,84)$ and decreased tumor growth (41).

Several cytokines and chemokines were confirmed to be involved in the recruitment of macrophages (91). For example, CCL2 is a member of the C-C type chemokine family secreted by tumor cells or TAMs to promote TAMs recruitment $(92,93)$. It has been reported that Bindarit, a specific inhibitor of CCL2, efficiently reduced the infiltration of macrophages and inhibited the growth of the osteosarcoma tumor (87).

Due to the pro-tumor effects of TAMs in osteosarcoma, decreasing TAMs present in the tumor by macrophageeliminating agents or some specific inhibitors may achieve an excellent therapeutic effect.

\section{Macrophage-Related Immune Checkpoint: CD47/SIRP $\alpha$}

The regulation of macrophages affects tumor development, and the application of immunomodulatory therapy to enhance antitumor effects is getting more and more attention (94). Specific blocking of receptor-ligand binding between macrophages and the tumor cells can enhance macrophage phagocytosis and antitumor activity, thus appears to be a promising strategy for cancer therapy $(95,96)$. CD47 is recognized as a 'don't eat me' signal, which binds to signal regulatory protein $\alpha(\operatorname{SIRP} \alpha)$ in the surface of macrophages resulting in the escape of phagocytosis and cell death $(97,98)$. As previously reported, CD47 is expressed in a variety of solid tumors and hematologic tumors (99). It was 
reported that CD47 was overexpressed in human osteosarcoma samples of different types than normal bone tissue or osteoma samples $(100,101)$. Similar to the preclinical studies in other tumors, CD47 can represent a useful therapeutic target in osteosarcoma. It has been confirmed that CD47 blockade by specific antibodies promotes the phagocytic effects of macrophages on osteosarcoma cells $(101,102)$. CD47 mAb treatment combined with chemotherapy increased the number of macrophages and further enhanced their phagocytic capabilities in osteosarcoma, thus produced a better outcome in the osteosarcoma-bearing mice model (103). Another study showed that SIRP- $\alpha$ knockout macrophages boost phagocytosis of osteosarcoma tumor cells (104).

Based on the preclinical evidence, several clinical trials are performed with CD47/SIRP $\alpha$ blocking using mAbs or Fc fusion proteins either alone or in combination with other therapies to treat different tumors (105-107). Those clinical trials are ongoing on multiple hematologic malignancies, including acute myeloid leukemia and myelodysplastic syndrome, and some advanced solid tumors such as liver cancer, non-small cell lung cancer, ovarian cancer, et al. (http://www.clinicaltrials.gov). However, there are no registered clinical trials on osteosarcoma patients so far. Compared with the first generation of CD47 targeting drugs terminated in trials due to their considerable side effects, the newly developed antibodies now being tested exhibit minimal binding to CD47-expressing red blood cells, minimizing their potential toxicity related to hemolytic anemia (108). For instance, Hu5F9-G4 (5F9), an anti-CD47 monoclonal antibody, was well tolerated in patients with advanced cancers and generated objective responses in the phase I trial (NCT02216409) (109). Moreover, 5F9 combined with rituximab (a CD20 antibody that targets B cells) exhibited promising activity in the treatment of B-cell lymphomas (NCT02953509) (110).

Although there are limited studies on anti-CD47/SIRP $\alpha$ therapy in osteosarcoma, these suggested strategies targeting CD47/SIRP- $\alpha$ that turn the 'don't eat me' signal off may be an efficient therapy in osteosarcoma.

\section{L-MTP-PE: Macrophages Activator}

Mifamurtide, as an immunostimulatory agent, is one of the most critical advances in macrophage targeted therapy of osteosarcoma (111). Liposomal muramyl tripeptide phosphatidyl ethanolamine (L-MTP-PE or mifamurtide) is derived from muramyl dipeptide (MDP), which is a component of bacterial cell walls (112). L-MTP$\mathrm{PE}$ may serve as an immunomodulator to activate macrophages and monocytes, and potentiate tumoricidal activity, causing the suppression of tumor growth and metastasis. L-MTP-PE is far more efficient than MDP in activating macrophages (113). Macrophages activated with L-MTP-PE resulted in tumor cell destruction without leading to resistance of tumor cells (114). Mifamurtide can upregulate the markers of M1 and M2 thus modulate macrophages into an M1/M2 intermediate phenotype, which achieved a dual role in anti-tumor and immunomodulatory functions (115).

Induction of soluble cytokines such as TNF- $\alpha$ and IL1- $\beta$ plays a role in the mechanism of action of L-MTP-PE on macrophages
(116). Moreover, these cytokines may contribute to the functions of other immune cells (58). L-MTP-PE administration stimulated the production of cytokines such as TNF- $\alpha$ and IL6 in patients with osteosarcoma (60).

Several studies also determined the efficacy of combination treatment with L-MTP-PE. Pahl et al. reported that in combination with interferon- $\gamma$, L-MTP-PE activated macrophages to inhibit the growth of osteosarcoma cells (116). L-MTP-PE alone or in combination with doxorubicin (DOX) was found to enhance the cytotoxic activity of macrophages against osteosarcoma in a canine model (117). In a clinical trial of patients with osteosarcoma, MTP combined with chemotherapy resulted in better clinical outcomes (118), including improved overall survival and a trend toward better event-free survival (119).

Existing evidence proves that L-MTP-PE acts as a potent activator of the immune response of macrophages and can be used in anti-osteosarcoma therapy.

\section{Regulation of Macrophage Polarization}

One of the critical characteristics of macrophages is their plasticity; thus, macrophages can respond to various stimuli in the TME, leading to a broad spectrum of activation phenotypes. As described above, the M2-like polarization of macrophages contributes to the pulmonary metastasis of osteosarcoma. Therefore, re-educating TAMs from immunosuppressive and pro-tumoral macrophages to the anti-tumor phenotype is a promising tumor treatment strategy, compared to depletion therapies targeting all macrophages.

Several approaches have been attempted to reprogram the TAMs, include cytokines, Toll-like receptors (TLRs) agonists, monoclonal antibodies (120). Many factors are known to repolarize TAMs towards an M1-like phenotype, such as IFN- $\gamma$, IL-12, leading to the activation of the STAT signaling pathway (121). TLRs are essential pathogen recognition receptors expressed by antigen-presenting cells, including macrophages. TLRs agonists induce the conversion of M2 to M1 phenotype to elicit anti-tumor effects $(122,123)$. For instance, Vidyarthi et al. reported the administration of TLR-3 ligand [poly (I: C)] in the murine colon tumor skewed the M2-macrophages to M1-phenotype and regressed the tumor growth in the IFN- $\alpha \beta$ signaling pathwaydependent manner (124). In addition to cytokines and TLR agonists, antibodies like anti-CSF1 and anti-CD40 were also applied to skew TAM polarization $(120,121)$.

In osteosarcoma, several drugs were elucidated to repolarize the macrophages and showed promising results. M1-like macrophages activated by LPS plus IFN- $\gamma$ showed suppression on osteosarcoma cell growth, and those effects were mediated by soluble factors secreted by macrophage in a TNF- $\alpha /$ IL-1independent manner (116). All-trans retinoic acid (ATRA) inhibited osteosarcoma invasion and metastasis by suppressing M2 polarization and secretion of MMP12 (84). Furthermore, this research team reported that ATRA could prevent M2type macrophage-mediated enhancement of osteosarcoma initiation and tumor cell stemness (35). Metformin, which was previously reported to elicit anti-tumor and anti-angiogenic effects by repolarization of macrophages, also contributes to 
osteosarcoma's growth inhibition via redirecting the metabolism polarization of macrophages $(125,126)$.

Intriguingly, gefitinib, an epidermal growth factor receptor (EGFR) inhibitor, altered pulmonary macrophage phenotype to block osteosarcoma invasion and reduce metastatic burden via inhibition of macrophage receptor-interacting protein kinase 2 (RIPK2) (42). Moreover, gefitinib altered macrophage phenotype and relieved surgery-accelerated metastasis and prolonged overall survival in mice model (83).

Fujiwara et al. identified a series of compounds screened from natural substances, namely, Onionin A1 (derived from Allium Sulfides) (127), epimedokoreanin B (a compound from Epimedii Herba) (127), and corosolic acid (CA)/oleanolic acid (OA) (both are triterpenoid compounds) (128). Those compounds possessed an inhibitory effect on the M2-macrophage polarization by suppressing STAT3 activation and preventing osteosarcoma progression and metastasis in osteosarcoma mice model.

Another research team also concentrated on the development of M2-type macrophage inhibitors/modulators, including wogonin (isolated from Scutellaria baicalensis roots) (129), dihydroxycoumarins (esculetin or fraxetin) (130), xanthoangelol and 4-hydroxyderricin (derived from Angelica keiskei roots) (131), resveratrol (132) and synthetic hydroxystilbenes (133). They examined that these substances effectively inhibit osteosarcoma growth and metastasis via suppression activation and differentiation of M2 macrophages.

Therefore, targeting the regulation of TAM polarization is a potential strategy for anti-osteosarcoma therapy.

\section{PD-1/PD-L1 Inhibitors}

PD-1/PD-L1 inhibitors as a means of tumor immunotherapeutics have been successfully applied clinically in treating a variety of tumors $(134,135)$. Their interaction with macrophages in the tumor microenvironment has also attracted increasing attention (136).

Several studies have revealed that PD-L1 expression was observed in primary and metastatic tumors of osteosarcoma patients $(46,137)$. PD-L1 positive tumors compared to PD-L1 negative tumors was significantly correlated with the presence of macrophages (137), particularly $\mathrm{CD}^{+} 8^{+}$cells $(46,138)$, implicating the potential role of macrophages in the anti-PD1/ PD-L1 treatment. TAMs also expressed PD-1 to participate in immune escape and inhibit phagocytosis and anti-tumor immunity (139). Moreover, the infiltrating macrophages were largely PD-L1 positive (up to 45\%) in osteosarcoma (137). This evidence suggests that targeting tumor-associated macrophages may represent an additional means to improve PD1/PD-L1 blockage therapy.

Additionally, some studies showed the effects of anti-PD1/ PD-L1 therapies by acting on macrophages. Anti-PD1 treatment decreased lung metastases of osteosarcoma through activating $\mathrm{CD} 86^{+} \mathrm{M} 1$ and reduced $\mathrm{CD} 16^{+} \mathrm{M} 2$ macrophages. Moreover, it was confirmed that macrophage depletion significantly compromised anti-PD1 efficacy (140). Similarly, it has been reported that anti-PD-L1 treatment blocks the PD-L1 signaling pathway, promoting macrophage proliferation and activation, leading to pro-inflammatory macrophage phenotypes (141). In an osteosarcoma mice model, the PD-L1 inhibitor also promoted monocyte maturation and returned macrophage M1/M2 marker expression to nearly normal status (36).

These studies suggest a new theoretical application of antiPD-1/PD-L1 antibodies alone or combination therapy to treat osteosarcoma.

\section{CONCLUSIONS}

In summary, macrophages are associated with clinical prognosis and possess clinically applicable potential in osteosarcoma treatment. As described above, macrophages, predominantly M2type TAMs, promote the osteosarcoma metastasis and exert protumor effects. Biomarkers, such as CD163, CD209, CCL18, et al., have been correlated with tumor progression in preclinical models of osteosarcoma. Furthermore, based on the immunoscore combined with a series of macrophages markers (not a single indicator), an algorithm can be constructed to differentiate patients and support diagnosis and the corresponding treatments and prognosis. For instance, Gomez and his colleagues (45) proposed a systematic analysis of CD68, CD163, CD8, PD1 and PDL-1 expression performed in osteosarcoma biopsies to stratify patients regarding their respective TME and suggested a therapeutic strategy targeting macrophages and other immunological factors. Development and validation of a TAM-based immune signature will afford a valuable clinical decision-making tool to screen subpopulations that respond and benefit most from the current therapies.

The current studies demonstrate that macrophages are involved in the local inflammation modulation, invasion, metastasis, and chemotherapy resistance of osteosarcoma and further interacted with other cells in TME. However, the distinct TAM subtypes may differentially react to osteosarcoma disease. Selective targeting the TAMs (such as CD163(+) TAMs $(38,142)$ ) rather than pandepletion demonstrated improved T-cell cytotoxic function tumor regression. Such information might prompt researchers to define specific TAM signatures and subsets in human biopsies for effective TAM targeting therapies. In fact, specific TAM subset(s) features and signals continuously evolve along with the disease history, regulating either pro- or anti-tumor activity. As such, the complex roles and detailed mechanisms of macrophages in osteosarcoma still need further exploration.

Based on present studies, the phenotypes or polarization states of macrophages of osteosarcoma were not well recognized. These results might appear to be contradictory due to the inconsistent definitions of M1/M2 markers and different specimens. Notably, the already described multiple biological functions of TAMs engaged in different in many types of tumors suggested that such definitions are insufficient and limiting and can hardly represent the whole dynamic process of TAMs in the TME. A thorough characterization of macrophages based on pathophysiological function rather than merely preexisting nomenclature is also needed.

Recently researchers, encouraged by successes in treatments with immune checkpoint blocking in some other types of malignancies, made efforts to capitalize on advances by extending those regimens to 


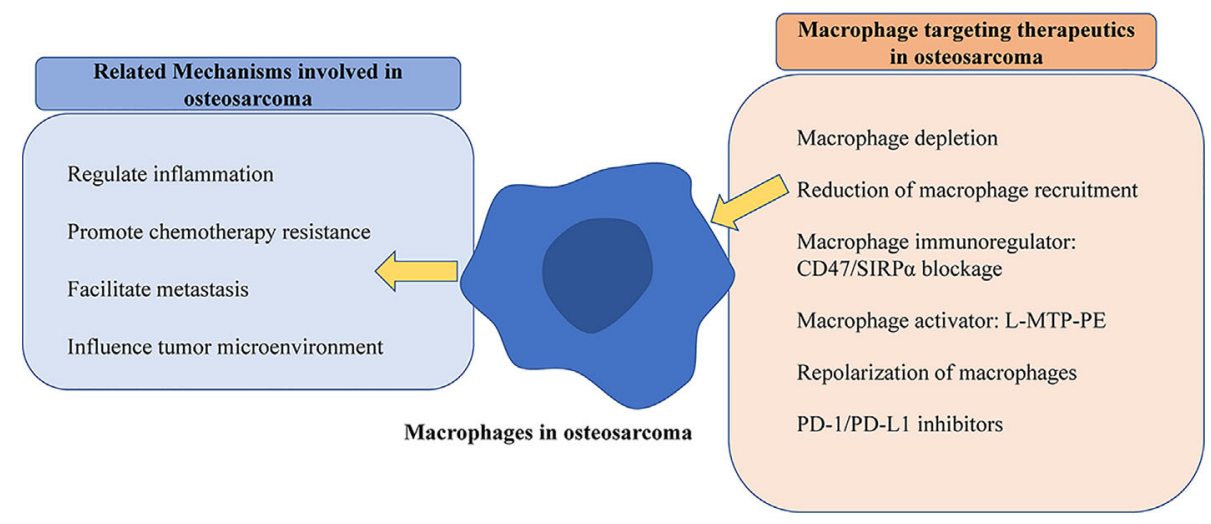

FIGURE 2 | Schematic diagram of mechanisms of macrophages and targeting strategies in osteosarcoma. The left part exhibits that macrophages play various roles, and the right part shows validated treatments by macrophage targeting in osteosarcoma.

osteosarcoma patients. However, osteosarcoma is characterized by relatively low immunogenicity, which may partly explain the low objective response to PD-1 Ab monotherapy treatment in the clinical trial $(143,144)$. A better understanding of macrophages allows the development of novel macrophage targets, and combines TAMtargeting approaches with other therapeutic approaches, which is of great significance to provoke immunotherapeutic responses in osteosarcoma patients. The primary clarified function and targeting therapeutics of macrophages in osteosarcoma were summarized by the schematic diagram shown in Figure 2.

\section{AUTHOR CONTRIBUTIONS}

Z-WL prepared the original draft of the manuscript. HX conceptualized, reviewed, and edited the manuscript, and supervised the study. P-PL, Z-XW, and C-YC revised and

\section{REFERENCES}

1. Whelan JS, Davis LE. Osteosarcoma, Chondrosarcoma, and Chordoma. J Clin Oncol (2018) 36(2):188-93. doi: 10.1200/JCO.2017.75.1743

2. Hu X, Rao S, Tan Y, Yin H, Luo M, Wang Z, et al. Fructose-coated Angstrom silver inhibits osteosarcoma growth and metastasis via promoting ROS-dependent apoptosis through the alteration of glucose metabolism by inhibiting PDK. Theranostics (2020) 10(17):7710-29. doi: $10.7150 /$ thno. 45858

3. Anderson ME. Update on Survival in Osteosarcoma. Orthop Clin North Am (2016) 47(1):283-92. doi: 10.1016/j.ocl.2015.08.022

4. Saraf AJ, Fenger JM, Roberts RD. Osteosarcoma: Accelerating Progress Makes for a Hopeful Future. Front Oncol (2018) 8:4. doi: 10.3389/ fonc.2018.00004

5. Wang Z, Wang Z, Li B, Wang S, Chen T, Ye Z. Innate Immune Cells: A Potential and Promising Cell Population for Treating Osteosarcoma. Front Immunol (2019) 10(1114):1114. doi: 10.3389/fimmu.2019.01114

6. Binnewies M, Roberts EW, Kersten K, Chan V, Fearon DF, Merad M, et al. Understanding the tumor immune microenvironment (TIME) for effective therapy. Nat Med (2018) 24(5):541-50. doi: 10.1038/s41591-018-0014-x

7. Corre I, Verrecchia F, Crenn V, Redini F, Trichet V. The Osteosarcoma Microenvironment: A Complex But Targetable Ecosystem. Cells-Basel (2020) 9(4):976. doi: 10.3390/cells9040976 edited the manuscript. All authors contributed to the article and approved the submitted version.

\section{FUNDING}

This research and the APC was funded by the National Natural Science Foundation of China (Grant Nos. 81670807, 81871822, 81702237, 81801395), the Excellent Young Scientist Award of National Natural Science Foundation of China (Grant No. 81522012), the Thousand Youth Talents Plan of China (Grant No. D1119003), the Medicine and Health Science and Technology Innovation Project of Chinese Academy of Medical Sciences (Grant No. 2019-RC-HL-024), the High Level Talent Gathering Project of Hunan Province (Grant Nos. 2017XK2039, 2018RS3029), and the Innovation Driven Project of Central South University (Grant Nos. 2016CX028, 2019CX014).

8. Roma-Rodrigues C, Mendes R, Baptista PV, Fernandes AR. Targeting Tumor Microenvironment for Cancer Therapy. Int J Mol Sci (2019) 20 (4):840. doi: 10.3390/ijms20040840

9. Alizadeh AA, Aranda V, Bardelli A, Blanpain C, Bock C, Borowski C, et al. Toward understanding and exploiting tumor heterogeneity. Nat Med (2015) 21(8):846-53. doi: 10.1038/nm.3915

10. Quail DF, Joyce JA. Microenvironmental regulation of tumor progression and metastasis. Nat Med (2013) 19(11):1423-37. doi: 10.1038/nm.3394

11. Vitale I, Manic G, Coussens LM, Kroemer G, Galluzzi L. Macrophages and Metabolism in the Tumor Microenvironment. Cell Metab (2019) 30(1):3650. doi: 10.1016/j.cmet.2019.06.001

12. Heymann MF, Lézot F, Heymann D. The contribution of immune infiltrates and the local microenvironment in the pathogenesis of osteosarcoma. Cell Immunol (2019) 343:103711. doi: 10.1016/j.cellimm.2017.10.011

13. Bolli E, Movahedi K, Laoui D, Van Ginderachter JA. Novel insights in the regulation and function of macrophages in the tumor microenvironment. Curr Opin Oncol (2017) 29(1):55-61. doi: 10.1097/CCO.0000000000000344

14. Miwa S, Shirai T, Yamamoto N, Hayashi K, Takeuchi A, Igarashi K, et al. Current and Emerging Targets in Immunotherapy for Osteosarcoma. J Oncol (2019) 2019:7035045. doi: 10.1155/2019/7035045

15. Kelleher FC, O'Sullivan H. Monocytes, Macrophages, and Osteoclasts in Osteosarcoma. J Adolesc Young Adult (2017) 6(3):396-405. doi: 10.1089/ jayao.2016.0078 
16. Italiani P, Boraschi D. From Monocytes to M1/M2 Macrophages: Phenotypical vs. Functional Differentiation. Front Immunol (2014) 5:514. doi: 10.3389/fimmu.2014.00514

17. Murray PJ, Allen JE, Biswas SK, Fisher EA, Gilroy DW, Goerdt S, et al. Macrophage Activation and Polarization: Nomenclature and Experimental Guidelines. Immunity (2014) 41(1):14-20. doi: 10.1016/j.immuni.2014. 06.008

18. Shapouri-Moghaddam A, Mohammadian S, Vazini H, Taghadosi M, Esmaeili SA, Mardani F, et al. Macrophage plasticity, polarization, and function in health and disease. J Cell Physiol (2018) 233(9):6425-40. doi: $10.1002 /$ jcp. 26429

19. Komohara Y, Fujiwara Y, Ohnishi K, Takeya M. Tumor-associated macrophages: Potential therapeutic targets for anti-cancer therapy. $A d v$ Drug Deliv Rev (2016) 99(Pt B):180-5. doi: 10.1016/j.addr.2015.11.009

20. Cassetta L, Pollard JW. Targeting macrophages: therapeutic approaches in cancer. Nat Rev Drug Discov (2018) 17(12):887-904. doi: 10.1038/ $\operatorname{nrd} .2018 .169$

21. Mantovani A, Marchesi F, Malesci A, Laghi L, Allavena P. Tumourassociated macrophages as treatment targets in oncology. Nat Rev Clin Oncol (2017) 14(7):399-416. doi: 10.1038/nrclinonc.2016.217

22. Segaliny AI, Mohamadi A, Dizier B, Lokajczyk A, Brion R, Lanel R, et al. Interleukin-34 promotes tumor progression and metastatic process in osteosarcoma through induction of angiogenesis and macrophage recruitment. Int J Cancer (2015) 137(1):73-85. doi: 10.1002/ijc.29376

23. Franklin RA, Liao W, Sarkar A, Kim MV, Bivona MR, Liu K, et al. The cellular and molecular origin of tumor-associated macrophages. Science (2014) 344(6186):921-5. doi: 10.1126/science.1252510

24. Xue J, Schmidt SV, Sander J, Draffehn A, Krebs W, Quester I, et al. Transcriptome-based network analysis reveals a spectrum model of human macrophage activation. Immunity (2014) 40(2):274-88. doi: 10.1016/j.immuni.2014.01.006

25. Martinez FO, Gordon S. The M1 and M2 paradigm of macrophage activation: time for reassessment. F1000Prime Rep (2014) 6:13. doi: 10.12703/ P6-13

26. Mosser DM, Edwards JP. Exploring the full spectrum of macrophage activation. Nat Rev Immunol (2008) 8(12):958-69. doi: 10.1038/nri2448

27. Kielbassa K, Vegna S, Ramirez C, Akkari L. Understanding the Origin and Diversity of Macrophages to Tailor Their Targeting in Solid Cancers. Front Immunol (2019) 10:2215. doi: 10.3389/fimmu.2019.02215

28. Franklin RA, Li MO. Ontogeny of Tumor-associated Macrophages and Its Implication in Cancer Regulation. Trends Cancer (2016) 2(1):20-34. doi: 10.1016/j.trecan.2015.11.004

29. Noy R, Pollard JW. Tumor-associated macrophages: from mechanisms to therapy. Immunity (2014) 41(1):49-61. doi: 10.1016/j.immuni.2014.06.010

30. Riabov V, Gudima A, Wang N, Mickley A, Orekhov A, Kzhyshkowska J. Role of tumor associated macrophages in tumor angiogenesis and lymphangiogenesis. Front Physiol (2014) 5:75. doi: 10.3389/fphys. 2014.00075

31. Coffelt SB, Hughes R, Lewis CE. Tumor-associated macrophages: effectors of angiogenesis and tumor progression. Biochim Biophys Acta (2009) 1796 (1):11-8. doi: 10.1016/j.bbcan.2009.02.004

32. Qian BZ, Pollard JW. Macrophage diversity enhances tumor progression and metastasis. Cell (2010) 141(1):39-51. doi: 10.1016/j.cell.2010.03.014

33. Inagaki Y, Hookway E, Williams KA, Hassan AB, Oppermann U, Tanaka Y, et al. Dendritic and mast cell involvement in the inflammatory response to primary malignant bone tumours. Clin Sarcoma Res (2016) 6(UNSP 13):13. doi: 10.1186/s13569-016-0053-3

34. Deng C, Xu Y, Fu J, Zhu X, Chen H, Xu H, et al. Reprograming the tumor immunologic microenvironment using neoadjuvant chemotherapy in osteosarcoma. Cancer Sci (2020) 111(6):1899-909. doi: 10.1111/cas.14398

35. Shao X, Xiang S, Chen Y, Zhang N, Cao J, Zhu H, et al. Inhibition of M2-like macrophages by all-trans retinoic acid prevents cancer initiation and stemness in osteosarcoma cells. Acta Pharmacol Sin (2019) 40(10):134350. doi: 10.1038/s41401-019-0262-4

36. Markel JE, Noore J, Emery EJ, Bobnar HJ, Kleinerman ES, Lindsey BA. Using the Spleen as an In Vivo Systemic Immune Barometer Alongside Osteosarcoma Disease Progression and Immunotherapy with alpha-PD-L1. Sarcoma (2018) 2018:8694397. doi: 10.1155/2018/8694397
37. Yang D, Liu K, Fan L, Liang W, Xu T, Jiang W, et al. LncRNA RP11361F15.2 promotes osteosarcoma tumorigenesis by inhibiting M2-Like polarization of tumor-associated macrophages of CPEB4. Cancer Lett (2020) 473:33-49. doi: 10.1016/j.canlet.2019.12.041

38. Han Q, Shi H, Liu F. CD163(+) M2-type tumor-associated macrophage support the suppression of tumor-infiltrating $\mathrm{T}$ cells in osteosarcoma. Int Immunopharmacol (2016) 34:101-6. doi: 10.1016/j.intimp.2016.01.023

39. Han Y, Guo W, Ren T, Huang Y, Wang S, Liu K, et al. Tumor-associated macrophages promote lung metastasis and induce epithelial-mesenchymal transition in osteosarcoma by activating the COX-2/STAT3 axis. Cancer Lett (2019) 440:116-25. doi: 10.1016/j.canlet.2018.10.011

40. Dumars C, Ngyuen J, Gaultier A, Lanel R, Corradini N, Gouin F, et al. Dysregulation of macrophage polarization is associated with the metastatic process in osteosarcoma. Oncotarget (2016) 7(48):78343-54. doi: 10.18632/ oncotarget.13055

41. Xiao Q, Zhang X, Wu Y, Yang Y. Inhibition of macrophage polarization prohibits growth of human osteosarcoma. Tumor Biol (2014) 35(8):7611-6. doi: 10.1007/s13277-014-2005-y

42. Maloney C, Kallis MP, Edelman M, Tzanavaris C, Lesser M, Soffer SZ, et al. Gefitinib inhibits invasion and metastasis of osteosarcoma via inhibition of macrophage Receptor Interacting Serine/Threonine Kinase 2. Mol Cancer Ther (2020) 19(6):1340-50. doi: 10.1158/1535-7163.MCT-19-0903

43. Buddingh EP, Kuijjer ML, Duim RAJ, Buerger H, Agelopoulos K, Myklebost O, et al. Tumor-Infiltrating Macrophages Are Associated with Metastasis Suppression in High-Grade Osteosarcoma: A Rationale for Treatment with Macrophage Activating Agents. Clin Cancer Res (2011) 17(8):2110-9. doi: 10.1158/1078-0432.CCR-10-2047

44. Yang X, Zhang W, Xu P. NK cell and macrophages confer prognosis and reflect immune status in osteosarcoma. J Cell Biochem (2019) 120(5):8792-7. doi: $10.1002 /$ jcb. 28167

45. Gomez-Brouchet A, Illac C, Gilhodes J, Bouvier C, Aubert S, Guinebretiere J, et al. CD163-positive tumor-associated macrophages and CD8-positive cytotoxic lymphocytes are powerful diagnostic markers for the therapeutic stratification of osteosarcoma patients: An immunohistochemical analysis of the biopsies from the French OS2006 phase 3 trial. Oncoimmunology (2017) 6(9):e1331193. doi: 10.1080/2162402X.2017.1331193

46. Koirala P, Roth ME, Gill J, Piperdi S, Chinai JM, Geller DS, et al. Immune infiltration and PD-L1 expression in the tumor microenvironment are prognostic in osteosarcoma. Sci Rep-Uk (2016) 6(30093):30093. doi: $10.1038 /$ srep30093

47. Su Y, Zhou Y, Sun Y, Wang Y, Yin J, Huang Y, et al. Macrophage-derived CCL18 promotes osteosarcoma proliferation and migration by upregulating the expression of UCA1. J Mol Med (2019) 97(1):49-61. doi: 10.1007/ s00109-018-1711-0

48. Halbrook CJ, Pontious C, Kovalenko I, Lapienyte L, Dreyer S, Lee HJ, et al. Macrophage-Released Pyrimidines Inhibit Gemcitabine Therapy in Pancreatic Cancer. Cell Metab (2019) 29(6):1390-9. doi: 10.1016/ j.cmet.2019.02.001

49. Gottfried E, Kunz-Schughart LA, Weber A, Rehli M, Peuker A, Müller A, et al. Expression of CD68 in non-myeloid cell types. Scand J Immunol (2008) 67(5):453-63. doi: 10.1111/j.1365-3083.2008.02091.x

50. Ruffell B, Coussens LM. Macrophages and therapeutic resistance in cancer. Cancer Cell (2015) 27(4):462-72. doi: 10.1016/j.ccell.2015.02.015

51. Maniecki MB, Moller HJ, Moestrup SK, Moller BK. CD163 positive subsets of blood dendritic cells: the scavenging macrophage receptors CD163 and CD91 are coexpressed on human dendritic cells and monocytes. Immunobiology (2006) 211(6-8):407-17. doi: 10.1016/j.imbio. 2006.05.019

52. Comi M, Avancini D, Santoni De Sio F, Villa M, Uyeda MJ, Floris M, et al. Coexpression of CD163 and CD141 identifies human circulating IL-10producing dendritic cells (DC-10). Cell Mol Immunol (2019) 17(1):95-107. doi: 10.1038/s41423-019-0218-0

53. Sánchez-Espiridión B, Martin-Moreno AM, Montalbán C, Medeiros LJ, Vega F, Younes A, et al. Immunohistochemical markers for tumor associated macrophages and survival in advanced classical Hodgkin's lymphoma. Haematologica (2012) 97(7):1080-4. doi: 10.3324/haematol.2011.055459

54. Ritter B, Greten FR. Modulating inflammation for cancer therapy. J Exp Med (2019) 216(6):1234-43. doi: 10.1084/jem.20181739 
55. Mantovani A, Allavena P, Sica A, Balkwill F. Cancer-related inflammation. Nature (2008) 454(7203):436-44. doi: 10.1038/nature07205

56. Chen YU, Xu SF, Xu M, Yu XC. Postoperative infection and survival in osteosarcoma patients: Reconsideration of immunotherapy for osteosarcoma. Mol Clin Oncol (2015) 3(3):495-500. doi: 10.3892/mco.2015.528

57. Jeys LM, Grimer RJ, Carter SR, Tillman RM, Abudu A. Post operative infection and increased survival in osteosarcoma patients: are they associated? Ann Surg Oncol (2007) 14(10):2887-95. doi: 10.1245/s10434007-9483-8

58. Kansara M, Teng MW, Smyth MJ, Thomas DM. Translational biology of osteosarcoma. Nat Rev Cancer (2014) 14(11):722-35. doi: 10.1038/nrc3838

59. Coley WB. II. Contribution to the Knowledge of Sarcoma. Ann Surg (1891) 14(3):199-220. doi: 10.1097/00000658-189112000-00015

60. Kleinerman ES, Jia SF, Griffin J, Seibel NL, Benjamin RS, Jaffe N. Phase II study of liposomal muramyl tripeptide in osteosarcoma: the cytokine cascade and monocyte activation following administration. J Clin Oncol (1992) 10(8):1310-6. doi: 10.1200/JCO.1992.10.8.1310

61. Shalapour S, Karin M. Pas de Deux: Control of Anti-tumor Immunity by Cancer-Associated Inflammation. Immunity (2019) 51(1):15-26. doi: 10.1016/j.immuni.2019.06.021

62. Sottnik JL, U'Ren LW, Thamm DH, Withrow SJ, Dow SW. Chronic bacterial osteomyelitis suppression of tumor growth requires innate immune responses. Cancer Immunol Immun (2010) 59(3):367-78. doi: 10.1007/ s00262-009-0755-y

63. Tuohy JL, Somarelli JA, Borst LB, Eward WC, Lascelles BDX, Fogle JE. Immune dysregulation and osteosarcoma: Staphylococcus aureus downregulates TGF-beta and heightens the inflammatory signature in human and canine macrophages suppressed by osteosarcoma. Vet Comp Oncol (2020) 18(1SI):64-75. doi: 10.1111/vco.12529

64. Link MP, Goorin AM, Miser AW, Green AA, Pratt CB, Belasco JB, et al. The effect of adjuvant chemotherapy on relapse-free survival in patients with osteosarcoma of the extremity. N Engl J Med (1986) 314(25):1600-6. doi: 10.1056/NEJM198606193142502

65. Bacci G, Longhi A, Versari M, Mercuri M, Briccoli A, Picci P. Prognostic factors for osteosarcoma of the extremity treated with neoadjuvant chemotherapy: 15-year experience in 789 patients treated at a single institution. Cancer-Am Cancer Soc (2006) 106(5):1154-61. doi: 10.1002/ cncr. 21724

66. Larionova I, Cherdyntseva N, Liu T, Patysheva M, Rakina M, Kzhyshkowska J. Interaction of tumor-associated macrophages and cancer chemotherapy. Oncoimmunology (2019) 8(7):1596004. doi: 10.1080/2162402X.2019.1596004

67. Wei F, Wang D, Wei J, Tang N, Tang L, Xiong F, et al. Metabolic crosstalk in the tumor microenvironment regulates antitumor immunosuppression and immunotherapy resisitance. Cell Mol Life Sci (2020). doi: 10.1007/s00018020-03581-0

68. Sanchez LR, Borriello L, Entenberg D, Condeelis JS, Oktay MH, Karagiannis GS. The emerging roles of macrophages in cancer metastasis and response to chemotherapy. J Leukoc Biol (2019) 106(2):259-74. doi: 10.1002/ JLB.MR0218-056RR

69. Liu J, Wu F, Zhou H. Macrophage-derived exosomes in cancers: Biogenesis, functions and therapeutic applications. Immunol Lett (2020) 227:102-8. doi: $10.1016 /$ j.imlet.2020.08.003

70. De Palma M, Lewis CE. Macrophage regulation of tumor responses to anticancer therapies. Cancer Cell (2013) 23(3):277-86. doi: 10.1016/ j.ccr.2013.02.013

71. Jinushi M, Chiba S, Yoshiyama H, Masutomi K, Kinoshita I, Dosaka-Akita H, et al. Tumor-associated macrophages regulate tumorigenicity and anticancer drug responses of cancer stem/initiating cells. Proc Natl Acad Sci USA (2011) 108 (30):12425-30. doi: 10.1073/pnas.1106645108

72. Shree T, Olson OC, Elie BT, Kester JC, Garfall AL, Simpson K, et al. Macrophages and cathepsin proteases blunt chemotherapeutic response in breast cancer. Genes Dev (2011) 25(23):2465-79. doi: 10.1101/gad.180331.111

73. DeNardo DG, Brennan DJ, Rexhepaj E, Ruffell B, Shiao SL, Madden SF, et al. Leukocyte complexity predicts breast cancer survival and functionally regulates response to chemotherapy. Cancer Discov (2011) 1(1):54-67. doi: 10.1158/2159-8274.CD-10-0028

74. Ruffell B, Chang-Strachan D, Chan V, Rosenbusch A, Ho CMT, Pryer N, et al. Macrophage IL-10 blocks CD8+ T cell-dependent responses to chemotherapy by suppressing IL-12 expression in intratumoral dendritic cells. Cancer Cell (2014) 26(5):623-37. doi: 10.1016/j.ccell.2014.09.006

75. Murdoch C, Muthana M, Coffelt SB, Lewis CE. The role of myeloid cells in the promotion of tumour angiogenesis. Nat Rev Cancer (2008) 8(8):618-31. doi: $10.1038 / \mathrm{nrc} 2444$

76. Li YS, Liu Q, Tian J, He HB, Luo W. Angiogenesis Process in Osteosarcoma: An Updated Perspective of Pathophysiology and Therapeutics. Am J Med Sci (2019) 357(4):280-8. doi: 10.1016/j.amjms.2018.12.004

77. Stockmann C, Doedens A, Weidemann A, Zhang N, Takeda N, Greenberg JI, et al. Deletion of vascular endothelial growth factor in myeloid cells accelerates tumorigenesis. Nature (2008) 456(7223):814-8. doi: 10.1038/ nature 07445

78. Belgiovine C, D'Incalci M, Allavena P, Frapolli R. Tumor-associated macrophages and anti-tumor therapies: complex links. Cell Mol Life Sci (2016) 73(13):2411-24. doi: 10.1007/s00018-016-2166-5

79. Lu X, Meng T. Depletion of tumor-associated macrophages enhances the anti-tumor effect of docetaxel in a murine epithelial ovarian cancer. Immunobiology (2019) 224(3):355-61. doi: 10.1016/j.imbio.2019.03.002

80. Nakasone ES, Askautrud HA, Kees T, Park JH, Plaks V, Ewald AJ, et al. Imaging tumor-stroma interactions during chemotherapy reveals contributions of the microenvironment to resistance. Cancer Cell (2012) 21(4):488-503. doi: 10.1016/j.ccr.2012.02.017

81. Liang X, Guo W, Ren T, Huang Y, Sun K, Zhang H, et al. Macrophages reduce the sensitivity of osteosarcoma to neoadjuvant chemotherapy drugs by secreting Interleukin-1 beta. Cancer Lett (2020) 480:4-14. doi: 10.1016/ j.canlet.2020.03.019

82. Yan B, Liu Q, Liu G, Huang X, Zhu G, Gao L, et al. Macrophage-derived exosomes mediate osteosarcoma cell behavior by activating AKT signaling. RSC Adv (2020) 10(9):5032-9. doi: 10.1039/c9ra07332a

83. Kallis MP, Maloney C, Blank B, Soffer SZ, Symons M, Steinberg BM. Pharmacological prevention of surgery-accelerated metastasis in an animal model of osteosarcoma. J Transl Med (2020) 18(1):183. doi: 10.1186/s12967020-02348-2

84. Zhou Q, Xian M, Xiang S, Xiang D, Shao X, Wang J, et al. All-Trans Retinoic Acid Prevents Osteosarcoma Metastasis by Inhibiting M2 Polarization of Tumor-Associated Macrophages. Cancer Immunol Res (2017) 5(7):547-59. doi: 10.1158/2326-6066.CIR-16-0259

85. Guo W, Li Y, Pang W, Shen H. Exosomes: A Potential Therapeutic Tool Targeting Communications between Tumor Cells and Macrophages. Mol Ther (2020) 28(9):1953-64. doi: 10.1016/j.ymthe.2020.06.003

86. Zhao S, Jiang Y, Xu N, Li Q, Zhang Q, Wang S, et al. SPARCL1 suppresses osteosarcoma metastasis and recruits macrophages by activation of canonical WNT/beta-catenin signaling through stabilization of the WNT-receptor complex. Oncogene (2018) 37(8):1049-61. doi: 10.1038/onc.2017.403

87. Chen P, Zhou J, Li J, Zhang Q, Zuo Q. TIPE1 suppresses osteosarcoma tumor growth by regulating macrophage infiltration. Clin Transl Oncol (2019) 21(3):334-41. doi: 10.1007/s12094-018-1927-z

88. Wolf-Dennen K, Gordon N, Kleinerman ES. Exosomal communication by metastatic osteosarcoma cells modulates alveolar macrophages to an M2 tumor-promoting phenotype and inhibits tumoricidal functions. Oncoimmunology (2020) 9(1):1747677. doi: 10.1080/2162402X.2020. 1747677

89. Dehne N, Mora J, Namgaladze D, Weigert A, Brüne B. Cancer cell and macrophage cross-talk in the tumor microenvironment. Curr Opin Pharmacol (2017) 35:12-9. doi: 10.1016/j.coph.2017.04.007

90. van Rooijen N, Hendrikx E. Liposomes for specific depletion of macrophages from organs and tissues. Methods Mol Biol (2010) 605:189-203. doi: 10.1007/978-1-60327-360-2_13

91. Lee HW, Choi HJ, Ha SJ, Lee KT, Kwon YG. Recruitment of monocytes/ macrophages in different tumor microenvironments. Biochim Biophys Acta (2013) 1835(2):170-9. doi: 10.1016/j.bbcan.2012.12.007

92. Li X, Yao W, Yuan Y, Chen P, Li B, Li J, et al. Targeting of tumourinfiltrating macrophages via CCL2/CCR2 signalling as a therapeutic strategy against hepatocellular carcinoma. Gut (2017) 66(1):157-67. doi: 10.1136/ gutjnl-2015-310514

93. Qian BZ, Li J, Zhang H, Kitamura T, Zhang J, Campion LR, et al. CCL2 recruits inflammatory monocytes to facilitate breast-tumour metastasis. Nature (7355) 2011) 475:222-5. doi: 10.1038/nature10138 
94. DeNardo DG, Ruffell B. Macrophages as regulators of tumour immunity and immunotherapy. Nat Rev Immunol (2019) 19(6):369-82. doi: 10.1038/ s41577-019-0127-6

95. Veillette A, Chen J. SIRPalpha-CD47 Immune Checkpoint Blockade in Anticancer Therapy. Trends Immunol (2018) 39(3):173-84. doi: 10.1016/ j.it.2017.12.005

96. Weiskopf K. Cancer immunotherapy targeting the CD47/SIRP $\alpha$ axis. Eur J Cancer (2017) 76:100-9. doi: 10.1016/j.ejca.2017.02.013

97. Liu X, Kwon H, Li Z, Fu YX. Is CD47 an innate immune checkpoint for tumor evasion? J Hematol Oncol (2017) 10(1):12. doi: 10.1186/s13045-0160381-z

98. Willingham SB, Volkmer JP, Gentles AJ, Sahoo D, Dalerba P, Mitra SS, et al. The CD47-signal regulatory protein alpha (SIRPa) interaction is a therapeutic target for human solid tumors. Proc Natl Acad Sci USA (2012) 109(17):6662-7. doi: 10.1073/pnas.1121623109

99. Jaiswal S, Jamieson CH, Pang WW, Park CY, Chao MP, Majeti R, et al. CD47 is upregulated on circulating hematopoietic stem cells and leukemia cells to avoid phagocytosis. Cell (2009) 138(2):271-85. doi: 10.1016/ j.cell.2009.05.046

100. Mohanty S, Yerneni K, Theruvath JL, Graef CM, Nejadnik H, Lenkov O, et al. Nanoparticle enhanced MRI can monitor macrophage response to CD47 mAb immunotherapy in osteosarcoma. Cell Death Dis (2019) 10 (2):36. doi: 10.1038/s41419-018-1285-3

101. Xu J, Pan X, Zhang S, Zhao C, Qiu B, Gu H, et al. CD47 blockade inhibits tumor progression human osteosarcoma in xenograft models. Oncotarget (2015) 6(27):23662-70. doi: 10.18632/oncotarget.4282

102. Fang S, Yin H, Song Z, Li R, Xie X, Gu Z. Anti-CD47 antibody eliminates bone tumors in rats. Saudi J Biol Sci (2019) 26(8):2074-8. doi: 10.1016/ j.sjbs.2019.09.011

103. Mohanty S, Aghighi M, Yerneni K, Theruvath JL, Daldrup-Link HE. Improving the efficacy of osteosarcoma therapy: combining drugs that turn cancer cell 'don't eat me' signals off and 'eat me' signals on. Mol Oncol (2019) 13(10):2049-61. doi: 10.1002/1878-0261.12556

104. Ray M, Lee Y, Hardie J, Mout R, Tonga GY, Farkas ME, et al. CRISPRed Macrophages for Cell-Based Cancer Immunotherapy. Bioconjug Chem (2018) 29(2):445-50. doi: 10.1021/acs.bioconjchem.7b00768

105. Jalil AR, Andrechak JC, Discher DE. Macrophage checkpoint blockade: results from initial clinical trials, binding analyses, and CD47-SIRP $\alpha$ structure-function. Antib Ther (2020) 3(2):80-94. doi: 10.1093/abt/tbaa006

106. Sukhbir Kaur KVCR. Preclinical and clinical development of therapeutic antibodies targeting functions of CD47 in the tumor microenvironment. Antib Ther (2020) 2020(2020-10-18):D41-7. doi: 10.1093/abt/tbaa017

107. Zhang W, Huang Q, Xiao W, Zhao Y, Pi J, Xu H, et al. Advances in AntiTumor Treatments Targeting the CD47/SIRPalpha Axis. Front Immunol (2020) 11:18. doi: 10.3389/fimmu.2020.00018

108. Petrova PS, Viller NN, Wong M, Pang X, Lin GHY, Dodge K, et al. TTI-621 $(\mathrm{SIRP} \alpha \mathrm{Fc})$ : A CD47-Blocking Innate Immune Checkpoint Inhibitor with Broad Antitumor Activity and Minimal Erythrocyte Binding. Clin Cancer Res (2017) 23(4):1068-79. doi: 10.1158/1078-0432.CCR-16-1700

109. Sikic BI, Lakhani N, Patnaik A, Shah SA, Chandana SR, Rasco D, et al. Firstin-Human, First-in-Class Phase I Trial of the Anti-CD47 Antibody Hu5F9G4 in Patients With Advanced Cancers. J Clin Oncol (2019) 37(12):946-53. doi: 10.1200/JCO.18.02018

110. Advani R, Flinn I, Popplewell L, Forero A, Bartlett NL, Ghosh N, et al. CD47 Blockade by Hu5F9-G4 and Rituximab in Non-Hodgkin's Lymphoma. N Engl J Med (2018) 379(18):1711-21. doi: 10.1056/NEJMoa1807315

111. Nardin A, Lefebvre ML, Labroquere K, Faure O, Abastado JP. Liposomal muramyl tripeptide phosphatidylethanolamine: Targeting and activating macrophages for adjuvant treatment of osteosarcoma. Curr Cancer Drug Targets (2006) 6(2):123-33. doi: 10.2174/156800906776056473

112. Ando K, Mori K, Corradini N, Redini F, Heymann D. Mifamurtide for the treatment of nonmetastatic osteosarcoma. Expert Opin Pharmaco (2011) 12 (2):285-92. doi: 10.1517/14656566.2011.543129

113. Sone S, Mutsuura S, Ogawara M, Tsubura E. Potentiating effect of muramyl dipeptide and its lipophilic analog encapsulated in liposomes on tumor cell killing by human monocytes. J Immunol (1984) 132(4):2105-10.

114. Fogler WE, Fidler IJ. Nonselective destruction of murine neoplastic cells by syngeneic tumoricidal macrophages. Cancer Res (1985) 45(1):14-8.
115. Punzo F, Bellini G, Tortora C, Pinto DD, Argenziano M, Pota E, et al. Mifamurtide and TAM-like macrophages: effect on proliferation, migration and differentiation of osteosarcoma cells. Oncotarget (2020) 11(7):687-98. doi: 10.18632 /oncotarget.27479

116. Pahl JHW, Kwappenberg KMC, Varypataki EM, Santos SJ, Kuijjer ML, Mohamed S, et al. Macrophages inhibit human osteosarcoma cell growth after activation with the bacterial cell wall derivative liposomal muramyl tripeptide in combination with interferon-gamma. J Exp Clin Cancer Res (2014) 33(1):27. doi: 10.1186/1756-9966-33-27

117. Kurzman ID, Shi FS, Vail DM, MacEwen EG. In vitro and in vivo enhancement of canine pulmonary alveolar macrophage cytotoxic activity against canine osteosarcoma cells. Cancer Biother Radio (1999) 14(2):121-8. doi: 10.1089/cbr.1999.14.121

118. Meyers PA, Schwartz CL, Krailo MD, Healey JH, Bernstein ML, Betcher D, et al. Osteosarcoma: the addition of muramyl tripeptide to chemotherapy improves overall survival-a report from the Children's Oncology Group. J Clin Oncol (2008) 26(4):633-8. doi: 10.1200/JCO.2008.14.0095

119. Kleinerman ES, Snyder JS, Jaffe N. Influence of chemotherapy administration on monocyte activation by liposomal muramyl tripeptide phosphatidylethanolamine in children with osteosarcoma. J Clin Oncol (1991) 9(2):259-67. doi: 10.1200/JCO.1991.9.2.259

120. Anfray C, Ummarino A, Torres Andón F, Allavena P. Current Strategies to Target Tumor-Associated-Macrophages to Improve Anti-Tumor Immune Responses. Cells-Basel (2019) 9(1):46. doi: 10.3390/cells9010046

121. van Dalen FJ, van Stevendaal M, Fennemann FL, Verdoes M, Ilina O. Molecular Repolarisation of Tumour-Associated Macrophages. Molecules (2018) 24(1):9. doi: 10.3390/molecules24010009

122. Belgiovine C, Digifico E, Anfray C, Ummarino A, Torres AF. Targeting TumorAssociated Macrophages in Anti-Cancer Therapies: Convincing the Traitors to Do the Right Thing. J Clin Med (2020) 9(10):3226. doi: 10.3390/jcm9103226

123. Shime H, Matsumoto M, Oshiumi H, Tanaka S, Nakane A, Iwakura Y, et al. Toll-like receptor 3 signaling converts tumor-supporting myeloid cells to tumoricidal effectors. Proc Natl Acad Sci USA (2012) 109(6):2066-71. doi: 10.1073/pnas.1113099109

124. Vidyarthi A, Khan N, Agnihotri T, Negi S, Das DK, Aqdas M, et al. TLR-3 Stimulation Skews M2 Macrophages to M1 Through IFN- $\alpha \beta$ Signaling and Restricts Tumor Progression. Front Immunol (2018) 9:1650. doi: 10.3389/ fimmu.2018.01650

125. Wang JC, Sun X, Ma Q, Fu GF, Cong LL, Zhang H, et al. Metformin's antitumour and anti-angiogenic activities are mediated by skewing macrophage polarization. J Cell Mol Med (2018) 22(8):3825-36. doi: 10.1111/jcmm.13655

126. Uehara T, Eikawa S, Nishida M, Kunisada Y, Yoshida A, Fujiwara T, et al. Metformin induces $\mathrm{CD} 1 \mathrm{lb}(+)$-cell-mediated growth inhibition of an osteosarcoma: implications for metabolic reprogramming of myeloid cells and anti-tumor effects. Int Immunol (2019) 31(4):187-98. doi: 10.1093/ intimm/dxy079

127. Nohara T, Fujiwara $\mathrm{Y}$, El-Aasr M, Ikeda T, Ono M, Nakano D, et al. Antitumor Allium Sulfides. Chem Pharm Bull (2017) 65(3):209-17. doi: 10.1248/cpb.c16-00844

128. Fujiwara Y, Takeya M, Komohara Y. A Novel Strategy for Inducing the Antitumor Effects of Triterpenoid Compounds: Blocking the Protumoral Functions of Tumor-Associated Macrophages via STAT3 Inhibition. BioMed Res Int (2014) 2014(348539):348539. doi: 10.1155/2014/348539

129. Kimura Y, Sumiyoshi M. Anti-tumor and anti-metastatic actions of wogonin isolated from Scutellaria baicalensis roots through anti-lymphangiogenesis. Phytomedicine (2013) 20(3-4):328-36. doi: 10.1016/j.phymed.2012.10.016

130. Kimura Y, Sumiyoshi M. Antitumor and antimetastatic actions of dihydroxycoumarins (esculetin or fraxetin) through the inhibition of M2 macrophage differentiation in tumor-associated macrophages and/or G(1) arrest in tumor cells. Eur J Pharmacol (2015) 746:115-25. doi: 10.1016/ j.ejphar.2014.10.048

131. Sumiyoshi M, Taniguchi M, Baba K, Kimura Y. Antitumor and antimetastatic actions of xanthoangelol and 4-hydroxyderricin isolated from Angelica keiskei roots through the inhibited activation and differentiation of M2 macrophages. Phytomedicine (2015) 22(7-8):759-67. doi: 10.1016/j.phymed.2015.05.005

132. Kimura Y, Sumiyoshi M. Resveratrol Prevents Tumor Growth and Metastasis by Inhibiting Lymphangiogenesis and M2 Macrophage 
Activation and Differentiation in Tumor-associated Macrophages. Nutr Cancer (2016) 68(4):667-78. doi: 10.1080/01635581.2016.1158295

133. Kimura Y, Sumiyoshi M, Baba K. Antitumor and Antimetastatic Activity of Synthetic Hydroxystilbenes Through Inhibition of Lymphangiogenesis and M2 Macrophage Differentiation of Tumor-associated Macrophages. Anticancer Res (2016) 36(1):137-48.

134. Gong J, Chehrazi-Raffle A, Reddi S, Salgia R. Development of PD-1 and PDL1 inhibitors as a form of cancer immunotherapy: a comprehensive review of registration trials and future considerations. J Immunother Cancer (2018) 6 (1):8. doi: 10.1186/s40425-018-0316-Z

135. He L, Li Z. B7-H3 and its role in bone cancers. Pathol Res Pract (2019) 215 (6):152420. doi: 10.1016/j.prp.2019.04.012

136. Cai J, Qi Q, Qian X, Han J, Zhu X, Zhang Q, et al. The role of PD-1/ $\mathrm{PD}-\mathrm{L} 1$ axis and macrophage in the progression and treatment of cancer. J Cancer Res Clin Oncol (2019) 145(6):1377-85. doi: 10.1007/s00432-01902879-2

137. Majzner RG, Simon JS, Grosso JF, Martinez D, Pawel BR, Santi M, et al. Assessment of Programmed Death-Ligand 1 Expression and TumorAssociated Immune Cells in Pediatric Cancer Tissues. Cancer-Am Cancer Soc (2017) 123(19):3807-15. doi: 10.1002/cncr.30724

138. Silva MA, Triltsch N, Leis S, Kanchev I, Tan TH, Van Peel B, et al. Biomarker recommendation for $\mathrm{PD}-1 / \mathrm{PD}-\mathrm{L} 1$ immunotherapy development in pediatric cancer based on digital image analysis of PD-L1 and immune cells. J Pathol Clin Res (2020) 6(2):124-37. doi: 10.1002/cjp2.152

139. Gordon SR, Maute RL, Dulken BW, Hutter G, George BM, McCracken MN, et al. PD-1 expression by tumour-associated macrophages inhibits phagocytosis and tumour immunity. Nature (2017) 545(7655):495-9. doi: 10.1038/nature22396

140. Dhupkar P, Gordon N, Stewart J, Kleinerman ES. Anti-PD-1 therapy redirects macrophages from an $\mathrm{M} 2$ to an $\mathrm{M} 1$ phenotype inducing regression of OS lung metastases. Cancer Med-Us (2018) 7(6):2654-64. doi: $10.1002 / \mathrm{cam} 4.1518$

141. Hartley GP, Chow L, Ammons DT, Wheat WH, Dow SW. Programmed Cell Death Ligand 1 (PD-L1) Signaling Regulates Macrophage Proliferation and Activation. Cancer Immunol Res (2018) 6(10):1260-73. doi: 10.1158/23266066.CIR-17-0537

142. Etzerodt A, Tsalkitzi K, Maniecki M, Damsky W, Delfini M, Baudoin E, et al. Specific targeting of CD163(+) TAMs mobilizes inflammatory monocytes and promotes T cell-mediated tumor regression. J Exp Med (2019) 216 (10):2394-411. doi: 10.1084/jem.20182124

143. Keung EZ, Burgess M, Salazar R, Parra ER, Rodrigues-Canales J, Bolejack V, et al. Correlative Analyses of the SARC028 Trial Reveal an Association Between Sarcoma-Associated Immune Infiltrate and Response to Pembrolizumab. Clin Cancer Res (2020) 26(6):1258-66. doi: 10.1158/10780432.CCR-19-1824

144. Tawbi HA, Burgess M, Bolejack V, Van Tine BA, Schuetze SM, Hu J, et al. Pembrolizumab in advanced soft-tissue sarcoma and bone sarcoma (SARC028): a multicentre, two-cohort, single-arm, open-label, phase 2 trial. Lancet Oncol (2017) 18(11):1493-501. doi: 10.1016/S1470-2045<(>17)30624-1

Conflict of Interest: The authors declare that the research was conducted in the absence of any commercial or financial relationships that could be construed as a potential conflict of interest.

Copyright (๑) 2020 Luo, Liu, Wang, Chen and Xie. This is an open-access article distributed under the terms of the Creative Commons Attribution License (CC BY). The use, distribution or reproduction in other forums is permitted, provided the original author(s) and the copyright owner(s) are credited and that the original publication in this journal is cited, in accordance with accepted academic practice. No use, distribution or reproduction is permitted which does not comply with these terms. 